\title{
Determinants of Immunization Coverage in Children 12-23 Months in Miga Local Government Area, Jigawa State Nigeria
}

\author{
Article by Nasiru Hassan Alhassan, Ashiru M. Hamza, Usaini Bala, Bala Musa \\ Kaugama. \\ Masters in Public Health, Texila American University, Nigeria \\ Email: nasirpharm94@gmail.com
}

\begin{abstract}
Background: There are high reported cases of pentavalent 3 vaccines dropout and low immunization coverage in Miga local government area (LGA), Jigawa State, Nigeria. This study aims to evaluate the determinants of the low immunization coverage in children aged 12-23 months in order to formulate/recommend public health interventions to revitalize the routine immunization activities in the Local government area.

Method: This is a cross-sectional study (using the WHO cluster sampling technique) conducted among 390 care givers who have eligible children between 12-23 months old using structured free tested questioner on routine immunization activities to find out the determining factors responsible for the low immunization coverage and high dropout rate of pentavalent vaccines. A stratified sampling method was used to select 30 clusters from 186 settlements. The Data collected was analyzed using the excel spread sheet and determinants responsible for the low coverage were identified.

Results: After differential analysis of the data collected, 5 factors were identified: maternal education, mass media exposure, community education and awareness campaign on routine immunization all other factors that prevented child from visiting health clinic such as not trusting vaccine by the parent, permission not granted by the husband, cost of transportation to the clinic ,non execution of planned outreaches by the health workers as major determinants responsible for wide gap in routine immunization coverage in the local government area.

Conclusion: Low immunization coverage has debilitating consequences on the lives of the children. To improve the immunization uptake, it is recommended that health education/promotion programs that focus on meeting the needs of the caregivers of the eligible children as well as continual social support should be developed and be part of the LGA's holistic public health/promotion program to save the underserved children.
\end{abstract}

Key Words: immunization, determinants, chi square, cross-sectional study, Miga.

\section{Introduction}

\subsection{Introduction/Background}

Active immunization/vaccination has been named one of the "Ten Great Public Health Achievements in the 20th Century" by American Centers for Disease Control and Prevention (CDC) (Jennifer.B.H.et al 2014).

\subsubsection{General objectives of the study}

The aim of the study was to examine the factors influencing the low routine immunization coverage in Miga LGA, Jigawa State, Nigeria in order to formulate effective public health education and promotion interventions strategies to improve the routine immunization coverage in the LGA 
South American Journal of Public Health

Special Edition May 2016

\subsubsection{Specific objectives}

1. To determine the political, socio-cultural and socio-economic factors associated with non-acceptance of routine immunization in Miga LGA.

2. To identify the determinants responsible for high dropout rate of DPT/PENTA in Miga LGA.

\subsection{Vaccine information}

The Nigerian Government introduce pentavalent vaccine to replace the currently used DPT vaccine in routine immunization (WHO, Africa 2012) with view to improve RI activities it is estimated that about 30,000 children life will be save(Vanguard ,2012) Pentavalent vaccine is a combination of five vaccines in one that prevent diphtheria, tetanus, whooping cough hepatitis $b$ and haemophilus influenza type b (WHO, Africa 2012) The new routine immunization schedule in Jigawa State/Nigeria is as follows :

3. AGE

4. Birth

5. 6 weeks

6. 10 weeks

7. 14 weeks

8. 9 months
ANTIGENS (VACCINES) GIVEN

BCG, OPVO, HepBO

OPV1, Pentavalent 1, PCV 1

OPV2, Pentavalent 2, PCV 2

OPV3, Pentavalent 3, PCV 3

Measles, Yellow Fever

\subsection{Study design}

A community-based cross sectional study design was appropriate to answer the research question. I was interested in identifying the full determinants of immunization coverage in miga LGAs, Jigawa State. A community-based cross-sectional study was conducted with mothers or caregivers of sampled children as our respondents.

\subsection{Inclusion criterion and data Source}

For a child to be eligible for sampling, he or she must have been between 12-23 months old at the time of the study. The primary respondent was the mother of the child; and in case of her absence, the father acted as the next respondent. In case of absence of both of them, an adult in the household who remained with the child for most of the time or had taken the child for immunization on at least one occasion is going to be interviewed (Nath et, al,(2007)

- Nath et al however used secondary data analysis in Bangladesh, Data from the 2004 Bangladesh Demographic and Health Survey $(\mathrm{N}=3530)$ was used. The data was analyzed using descriptive and multiple logistic regression methods

- Togbo et al (2014) study made use of the 2008 Nigeria demographic health survey (NDHS) children data. According to the study report, data on immunization were collected from vaccination cards and base on what information is recorded in the national data bank.

- While in this current study we used primary data using semi structured questionnaire.

\subsection{Sample size determination}

The sample size used for this study was determined using the methods recommended by the WHO for immunization coverage cluster survey (WHO, 2005) The WHO 30-cluster sampling technique was used for the selection of the subjects. Mother, father or relative of a total of 390 children with 13 children per cluster were interviewed in the study, using a free tested structured questionnaire adopted from the Nigeria immunization survey questionnaire. Also as recommended by the WHO, children aged 12-23 months children were sample since final primary immunization is at 9 months (WHO, 2005). For the purpose of this study each settlement is considered as a cluster. According to WHO, normally the clusters used for immunization are villages, town blocks, and census data WHO 2015. We interviewed mothers of these children using structured questionnaire to collect data on socio-demographic characteristics, knowledge on immunization, vaccination status of children and reasons for 
non-vaccination. Fully immunized child is define as a child who had received one dose of BCG, three doses of oral polio vaccine, three doses of Diphtheria-Pertusis-Tetanus vaccine (DPT/Pentavalent) and one dose of measles vaccine by 12 months of age. The researcher performed bivariate analysis and Chi-square analysis using excel spread sheet.

Using Research advisors 2006 sample size time table (http://research.advisors.com) under the conditions of acceptable probability of incorrectly rejecting the hypothesis that the is no difference in immunization coverage between the places, significant level is normally 0.05 or 0.01 is used, that is $5 \%$ or $1 \%$ margin interval thus we used sample size webcam table (table

1). The formula used for these calculations was:

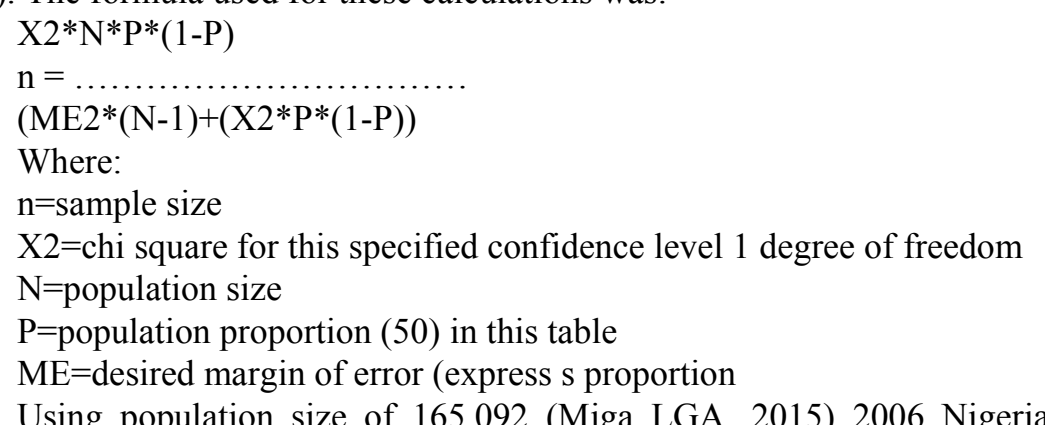

Using population size of 165,092 (Miga LGA, 2015) 2006 Nigeria population census extrapolated, confidence interval level of $95 \%$ and margin of error degree of accuracy $5 \%$ according to the web cam table the sample size is 383 ,. According to WHO cluster sampling we sample 30 clusters $=383 / 30=12.77$ which was approximately 13 . Thus we sampled 13 households in 30 clusters making a total of 390 children $(13 * 30=390$

\subsection{Sampling method}

The two-stage WHO cluster sampling technique was utilized to sample eligible children.

Stage one: Selection of clusters: At stage one; the researcher selected 30 clusters from the available 186 clusters based on probability proportionate to the size of the population. To select the 30 clusters, the following steps were undertaken: - We listed the names of all the settlement in Miga LGA in alphabetical order (1-186) using excel spread sheet, then we divided 186 by 30 and that gave us 6 and we chose a number multiple of 6 and selected a corresponding village name/settlements e.g. $(6,12.18,24,30,36,42, \ldots \ldots \ldots)$ to make 30 settlements.

Stage 2: Selection of households- at stage two, we selected 13 households from each of the 30 clusters selected at stage one. According to WHO cluster sampling we sample 30 clusters $=(383 / 30=12.77)$ which is approximately 13 . Thus we sampled 13 house hold in 30 clusters making a total of 390 children $(13 * 30=390)$

The first household in each cluster was selected randomly. Subsequent households were selected contiguously in the right direction until the number of households for that cluster was completed. From each selected household, one eligible child was selected. If a selected household had more than one eligible child, only one was randomly selected using table of numbers. If a selected household had no eligible child, the next contiguous household was visited and one eligible child selected.

\subsection{Data collection}

Data for the study was collected by female data collectors accompanied by local guide as recommended by WHO guide line (WHO, 2005) using free tested structured interviewadministered questionnaire. Data collected on socio-demographic characteristics of mothers and children, knowledge and attitudes of mothers/care givers regarding RI and IPDs, vaccination status of children and reasons for non-vaccination. A number of supervisors were also deployed in carrying out the study. A 2 days training was conducted on house hold sampling technique and how to administer the questionnaire. 
South American Journal of Public Health

Special Edition May 2016

\subsubsection{Random table number selection}

According to this survey guide line any house hold with more than one eligible child the selection is base on a random table number, to avoid interviewer/selection biases.

\subsubsection{Validity of RI antigens}

For any antigen administered to a child to be considered valid, that antigen must have been administered at the recommended age; and for multiple dose antigens, not less than 4 weeks interval between the doses (WHO, 2005). A child's BCG vaccine is considered valid, if a scar was present irrespective of whether the vaccination was recorded on the card or obtained by history. BCG vaccination recorded on the card but without a scar was also considered valid (WHO 2005.

\subsubsection{Vaccination status of children}

Based on the type and doses of valid RI antigens received, the researcher categorized the children as fully immunized, partially immunized, or un-immunized. The categories of vaccination status were defined as follows:

- Fully immunized child: a child who had received one dose of BCG, three doses of OPV (excluding OPV given at birth), three doses of DPT vaccine and one dose of measles vaccine by 12 months of age (Nath et al, 12007);

- Partially immunized child: a child who missed at least any one of the above doses;

- Un-immunized child: a child who had not received any vaccine by 12 months of age.

\subsection{Data analysis}

The data was substantiated and analyzed using Excel Spread-Sheet version 7. Data was cleaned and normality was checked before analysis. Descriptive statistics was used to summarize the socio-demographic characteristics of the study population and is presented as numbers, percentages and $95 \%$ confidence intervals (CI) as appropriate. The appropriate statistical analysis of the data using univariate analysis was used to obtain frequency and proportions were utilized and then bivariate and Chi-square analysis was used appropriately to identify factors that determine full immunization status.

\subsection{Ethical considerations}

Approval for the conduct of this study was sought from the ethical committee of Jigawa State Operational Research Advisory Committee (ORAC) And State Ministry of Health which is in accordance with the principles of the declaration of Helsinki. Data collection commenced immediately after ethical approval was granted. Written informed consent was also obtained from each caregiver prior to participation.

Participants were made aware that their participation was voluntary and that they can withdraw at any time without any penalty. If a potential participant was not interested in participating, his/her participation will not be pursued. While the names of the participants will be known in order to get their written informed consent for the interview, only the researcher will have access to the participants' names. Identity number will be used for all sources of data. Hence, no one will be able to identify any individual member of the study. Hard copies of questionnaire were kept in separate files and will be destroyed after eight years. Data will only be used for the purpose which it was requested. No known harm to study participants was apparent. Study participants will receive no compensation for their participation.

In addition, to minimise invasion of privacy, recruitment of the participants was taken into account the potential participant's right to refuse without the researcher knowing his/her decision. This action allow for the potential participants to make independent choices other than imposing choices on them. 


\section{Results and discussion}

\subsection{Vaccination coverage}

As shown in Table 4a-c, the BCG/OPV0 has the highest percentage coverage of $25.6 \%$ followed by Pentavalent 1 with $16.4 \%$, Pentavalent 2 with $10.5 \%$, while that of DPT 3/pentavalent 3 was $8.5 \%$. Fully immunized/complete stood at $7 \%$ percent. Receiving of pentavalent and OPV decreases with higher doses. Measles recorded higher doses then penta3 this may not be unconnected with health camp vaccination during polio campaigns in higher risk wards. $19 \%$ of the children were partially immunized that is they did not receive one or more vaccines as scheduled before the age of 12 months this resulted in a very high DPT/ penta3 drop out of $48.5 \%$, which is by far higher than the $10 \%$ official limit by the WHO . Percentage unimmunized stood as high as $74.4 \%$ that means in every 10 children $12-23$ months sampled in Miga LGA in 2015, only 4 children had contact with routine immunization services. Wide gap exists in immunization coverage between urban settlements and the rural settlements. Urban recorded $25 \%$ fully immunized against $4.9 \%$ of the rural settlement, also partially immunized in urban settlement of Miga stood at $42.1 \%$ while that of rural stood at $18.5 \%$.

\subsection{Differentials in childhood immunization coverage}

The determinants of routing immunization coverage in Miga LGA were assessed. The main determinants tested for the low performance in the RI coverage are: sex, parity, maternal education, father's education, mass media awareness, knowledge and information on routine immunization.

(a) Sex: according to bivariate analysis conducted, it was shown that being a male child is twice associated with being fully immunized (8\%) than the female child with (4\%) see table 2a. Chi square analysis conducted with 2 degree of freedom (df2) gave $x^{2}=0.527, p>0.05, \alpha$ $=0.687$ the $\mathrm{p}$ value is $>0.05$ thus we cannot reject the Ho (null hypothesis). However, we cannot conclude that sex and completeness of routine immunization are statistically related/ insignificance this may be due to higher number of males (53.4\%) than female (46.5) in the sampled population. Also in partially immunized category, male and female children are almost equal in number with male $(9 \%)$, female $(8 \%)$ and unimmunized categories male (72\%) female (76\%).

(b) Parity: women who gave birth to $1-2$ children achieved up to $50 \%$ of the fully immunized while women who gave birth to $3-4$ children had only $15.4 \%$ in the fully immunized category. $74 \%$ of children given birth by women with $5+$ (plus) are not immunized However, chi square analysis shows that $\left(\mathrm{x}^{2}=0.61 \mathrm{p}>0.05, \alpha=0.47\right)$. The $p$-value is 0.47 which is $>\alpha$, this result is NOT statistically significant. We therefore cannot reject the H0 (null hypothesis) and we cannot conclude that (parity and immunization) are statistically related.

(c) Maternal education: was found to be one of the major determinants of immunization coverage in Miga. $100 \%$ of mothers with post-secondary education have fully immunized their children while mothers with none formal or Qur;anic education had only $1.5 \%$ of their children as fully immunized ( table 2c) and constitute $54 \%$ and $56.6 \%$ of the partially immunized and unimmunized children respectively. Chi square analysis shows that The $p$ value is less than $0.05 \%$ which is $<\alpha$, this result is statistically significant. Reject the $\mathrm{H} 0$ and concluded that maternal education and full immunization coverage are related.

(d) Father's education: (df4), the result shows that fathers with post-secondary education had $(71.4 \%)$ of their children as fully immunized and $28.6 \%$ as partially immunized with none as unimmunized in their category. Also $84 \%$ children whose fathers had primary school education are fully immunized while $79 \%$ of children whose father had Quranic education with no formal education are found to be unimmunized (table $2 \mathrm{~d})\left(\mathrm{x}^{2}=0.84 \mathrm{p}>0.05 \alpha 1.14\right) \mathrm{p}$ value is $>0.05 \% \alpha$ is 1.14 , hence we cannot not conclude its significance statistically. 
South American Journal of Public Health

Special Edition May 2016

(e) Mass media awareness: (Lack of information and knowledge ) was also found to be one of the determinants, with radio having the highest audience $27.2 \%$ followed by health worker awareness $17.4 \%$, polio vaccination team announcement $15.9 \%$ is ahead of town announcer with $12.1 \%$. Fully immunized status revealed that $50 \%$ of the parent got their information on immunization from health workers, followed by $23 \%$ from polio vaccination team and $11.5 \%$ from radio and $8 \%$ from town announcers. Chi square analysis shows that $\left(\mathrm{x}^{2}=13.3, \mathrm{p}<0.05^{\alpha}=0.001\right) \mathrm{p}$ value is less than alpha $=0.001$ at 1 degree of freedom and thus conclude that this result is statistically significant. The researcher rejected the $\mathrm{H} 0$ and concluded that care giver awareness and full immunization coverage are related.

(f) Unaware of need for vaccination: account for $24.1 \%$ and became one of the major reasons given by the care givers as reason for not vaccinating their children, $10 \%$ said they do not trust vaccine, while $8 \%$ said their husband will not allow their child to be vaccinated see (table 5 below). Chi square analysis read (df1) $\mathrm{x}^{2}=25.5, \mathrm{p}<0.05 \alpha=0.001 \mathrm{p}$ value is $<\alpha$. The $p$ value is 0.0382 which is $<\alpha$, this result is statistically significant. The researcher rejected the $\mathrm{H} 0$ and concludes that there is a strong relationship between not completing RI and unaware of need / not trusting vaccines the two variables are related.

- Also when asked 'why did the child had no RI card', they responded as $62.3 \%$ of the children never want to clinic because of RI followed by $13.3 . \%$ who said their RI card is lost (table 6)

- When asked 'What information would help mothers decide to vaccinate their children through routine immunization services', the care givers responded as shown in table 7 below, $25.4 \%$ said they need more information on what diseases vaccines protect against, $22.3 \%$ says they need more information on why vaccination of their child is important $15.9 \%$ need more information on safety of the vaccines while $11.3 \%$ said they need information on side effect of the vaccines.

Table 4.1: Socio-demographic factors of survey population with analyzed responses by the care givers in Miga LGA, Jigawa, Nigeria

Table2a

\begin{tabular}{|l|c|l|l|l|l|}
\hline $\begin{array}{c}\text { Characteristics } \\
\text { Sex }\end{array}$ & $\begin{array}{c}\text { MIGA } \\
\text { LGA } \\
\text { Sample } \\
\text { population } \\
\mathbf{N}(\%)\end{array}$ & $\begin{array}{c}\text { Fully } \\
\text { immunized } \\
\mathbf{N}(\%)\end{array}$ & $\begin{array}{c}\text { Partially } \\
\text { immunized } \\
\mathbf{N}(\%)\end{array}$ & $\begin{array}{c}\text { Not } \\
\text { immunized } \\
\mathbf{N}(\%)\end{array}$ & $\begin{array}{c}\text { Differential ,p, } \\
\mathbf{a x}^{2}\end{array}$ \\
\hline & $210(53.8)$ & $18(8.0)$ & $40(19.0)$ & $152(72.0)$ & \\
\hline Female & $180(46.2)$ & $8(4.0)$ & $34(18.0)$ & $138(76.0)$ & $\begin{array}{c}\mathrm{x}^{2}=0.527 \mathrm{p}>0.0 \\
5, \alpha=0.687\end{array}$ \\
\hline Unknown & $0(00.0)$ & $0(00.0)$ & $0(00.0)$ & $0(00.0)$ & \\
\hline
\end{tabular}

Table 2b

\begin{tabular}{|l|l|l|l|l|l|}
\hline \multicolumn{1}{|c|}{ Parity } & $\begin{array}{c}\text { Sample } \\
\text { population } \\
\mathbf{N}(\%)\end{array}$ & $\begin{array}{c}\text { Fully } \\
\text { immunized } \\
\mathbf{N}(\%)\end{array}$ & $\begin{array}{c}\text { Partially } \\
\text { immunized } \\
\mathbf{N}(\%)\end{array}$ & $\begin{array}{c}\text { Not } \\
\text { immunized } \\
\mathbf{N}(\%)\end{array}$ & Differential ,p, $\mathbf{a x}^{2}$ \\
\hline 1-2 children & $138(35.4)$ & $13(50)$ & $30(40.6)$ & $95(32.7)$ & $\mathrm{x}^{2}=0.61 \mathrm{p}>0.05, \alpha=0.47$ \\
\hline 3-4 children & $130(33.3)$ & $4(15.4)$ & $22(29.7)$ & $104(35.8)$ & \\
\hline 5+ children & $122(31.3)$ & $9(34.6)$ & $22(29.7)$ & $91(31.4)$ & \\
\hline $\begin{array}{l}\text { Missing/Don't } \\
\text { Know }\end{array}$ & $0(00.0)$ & $0(00.0)$ & $0(00.0)$ & $0(00.0)$ & \\
\hline
\end{tabular}


Table 2c

\begin{tabular}{|l|l|l|l|l|l|}
\hline $\begin{array}{c}\text { Highest } \\
\text { level of } \\
\text { maternal } \\
\text { education }\end{array}$ & $\begin{array}{c}\text { Sample } \\
\text { population } \\
\mathbf{N}(\%)\end{array}$ & $\begin{array}{c}\text { Fully } \\
\text { immunized } \\
\mathbf{N}(\%)\end{array}$ & $\begin{array}{c}\text { Partially } \\
\text { immunized } \\
\mathbf{N}(\%)\end{array}$ & $\begin{array}{c}\text { Not } \\
\text { immunized } \\
\mathbf{N}(\%)\end{array}$ & $\begin{array}{c}\text { Differential ,p, } \\
\mathbf{a x}^{\mathbf{2}}\end{array}$ \\
\hline None & $199(51.0)$ & $3(1.5)$ & $32(43.2)$ & $164(82.4)$ & $\begin{array}{l}\mathrm{x}^{2}=17.71, \\
\mathrm{p}<0.05 \alpha=0.013\end{array}$ \\
\hline Primary & $32(8.2)$ & $4(12.5)$ & $13(17.6)$ & $15(46.9)$ & \\
\hline Secondary & $14(3.6)$ & $3(21.4)$ & $5(35.7)$ & $6(42.9)$ & \\
\hline $\begin{array}{l}\text { Post- } \\
\text { secondary }\end{array}$ & $4(1.03)$ & $4(100)$ & $0(00)$ & $0(00)$ & \\
\hline $\begin{array}{l}\text { Quranic } \\
\text { schools }\end{array}$ & $141(36.1)$ & $12(8.5)$ & $24(17.0)$ & $105(74.5)$ & \\
\hline
\end{tabular}

Table 2d

\begin{tabular}{|l|l|l|l|l|l|}
\hline $\begin{array}{c}\text { Highest level of } \\
\text { household head } \\
\text { education }\end{array}$ & $\begin{array}{c}\text { Sample } \\
\text { population } \\
\text { N (\%) }\end{array}$ & $\begin{array}{c}\text { Fully } \\
\text { immunized } \\
\text { N(\%) }\end{array}$ & $\begin{array}{c}\text { Partially } \\
\text { immunized } \\
\text { N(\%) }\end{array}$ & $\begin{array}{c}\text { Not } \\
\text { immunized } \\
\mathbf{N}(\%)\end{array}$ & \\
\hline None & $90(23.1)$ & $2(2.3)$ & $19(21.1)$ & $69(76.7)$ & $\begin{array}{l}\mathrm{x}^{2}=0.84 \mathrm{p}>0 . \\
05 \alpha 1.14\end{array}$ \\
\hline Primary & $25(6.4)$ & $0(0.0)$ & $4(20.0)$ & $21(84.0)$ & \\
\hline Secondary & $20(5.1)$ & $4(20.0)$ & $12(60.0)$ & $4(20.0)$ & \\
\hline Post-secondary & $7(1.8)$ & $5(71.4)$ & $2(28.6)$ & $0(0.0)$ & \\
\hline Quranic schools & $248(63.6)$. & $15(6.1)$ & $37(14.9)$ & $196(79.0)$ & \\
\hline Rural & $364(\mathbf{9 3 . 3 )}$ & $20(5.5 \%)$ & $67(90.5)$ & $287(99.0)$ & \\
\hline Total & 390 & 26 & 74 & 290 & \\
\hline
\end{tabular}

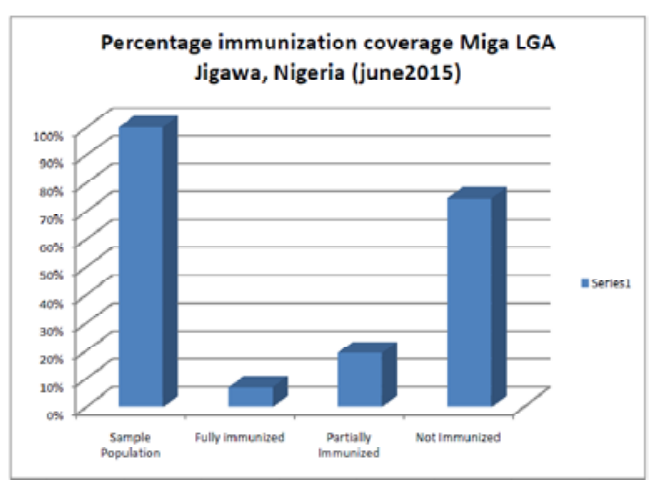

Figure 4.1: Comparison of the percentage coverage of immunization in children 12-23 months between fully, partial and not immunized in Miga LGA Jigawa State, Nigeria

Table 4.2: Showing the result of the immunization coverage by antigen Miga LGA Nigeria June 2015

\begin{tabular}{|l|l|l|l|}
\hline \multicolumn{1}{|c|}{ AGE } & $\begin{array}{c}\text { ANTIGENS (VACCINES) } \\
\text { GIVEN }\end{array}$ & $\begin{array}{c}\text { NUMBER OF } \\
\text { CHILDREN } \\
\text { IMMUNIZED }\end{array}$ & $\begin{array}{c}\text { PERCENTAGE } \\
\text { COVERAGE }\end{array}$ \\
\hline Birth & BCG, OPV0, HepB0 & 100 & 25.6 \\
\hline 6 weeks & OPV1, Pentavalent 1, PCV 1 & 64 & 16.4 \\
\hline 10 weeks & OPV2, Pentavalent 2, PCV 2 & 41 & 10.5 \\
\hline 14 weeks & OPV3, Pentavalent 3, PCV 3 & 33 & 8.5 \\
\hline 9 months & Measles, Yellow Fever & 36 & 9.2 \\
\hline $\begin{array}{l}\text { FULLY } \\
\text { IMMUNIZED }\end{array}$ & ALL & 26 & 6.7 \\
\hline
\end{tabular}


South American Journal of Public Health

Special Edition May 2016

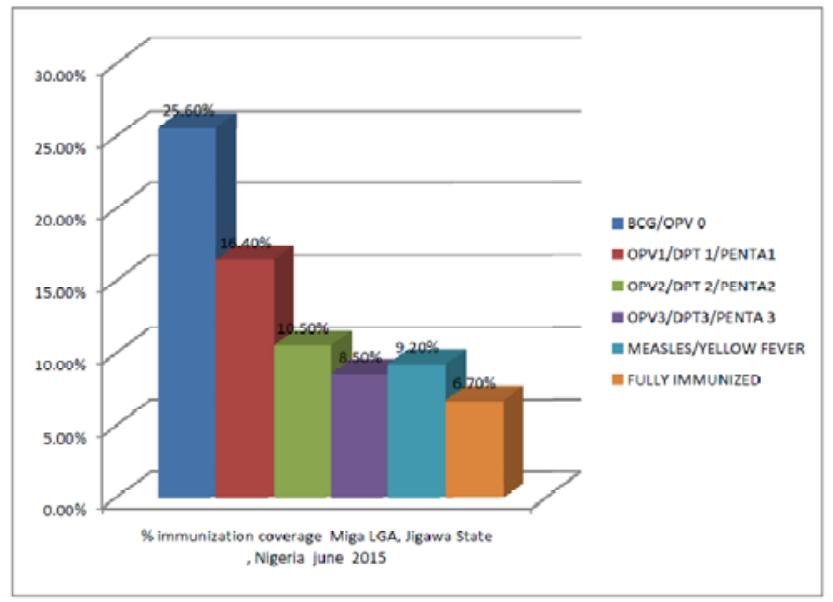

Figure 4.2: Bar chart showing Percentage Immunization Coverage by antigen Miga LGA Nigeria

Percentage Drop out $=$ Penta 1 minus $(-)$ Penta3/(divided by)Penta $1 *($ times $) 100$ $=(64-33 / 61) * 100$

Table 4.3: Source of information about Routine Immunization in Miga LGA, Jigawa Nigeria

\begin{tabular}{|c|c|}
\hline $\begin{array}{c}\text { Source of information about routine } \\
\text { immunization }\end{array}$ & $\mathbf{N}(\%) x^{2}=13.3, p<0.05 \alpha=0.001$ \\
\hline Health worker & $68(17.4)$ \\
\hline Polio campaign vaccinators & $62(15.9)$ \\
\hline Loud speaker/town announcer & $47(12.1)$ \\
\hline Poster/banner & $11(2.8)$ \\
\hline Radio & $106(27.2)$ \\
\hline Television & $4(1.0)$ \\
\hline Mobile telephone/SMS & $5(1.3)$ \\
\hline Newspapers/magazines & $4(1.0)$ \\
\hline Husband/family/neighbor/friends & $9(2.0)$ \\
\hline Women's groups & $4(1.0)$ \\
\hline Mosque/church & $1(0.3)$ \\
\hline Community leader & $16(4.1)$ \\
\hline Community mobilizer/VCM & $17(4.4)$ \\
\hline Not heard of routine immunization before & $14(3.6)$ \\
\hline Don't know & $15(5.4)$ \\
\hline Missing & $0(0.0)$ \\
\hline Total & 390 \\
\hline
\end{tabular}

Table 4.4: Reasons why did the child not receive all of his/her vaccinations through routine health services?

\begin{tabular}{|l|l|}
\hline \multicolumn{1}{|c|}{ Reasons } & \multicolumn{1}{|c|}{$\begin{array}{c}\mathrm{x}^{2}=25.5, \mathrm{p}>0.05 \alpha=0.001 \\
\mathbf{N}(\%)\end{array}$} \\
\hline Unaware of need for vaccination & $0(\mathrm{o})$ \\
\hline Did not know needed other vaccine & $15(3.9)$ \\
\hline Feel vaccination not important & $33(8.5)$ \\
\hline Do not trust vaccines & $39(10)$ \\
\hline Fear of side effect/ adverse event & $21(5.4)$ \\
\hline Cultural/ religious reasons & $11(2.8)$ \\
\hline Unaware of place/time of vaccination & $6(1.5)$ \\
\hline place of vaccination too far/difficult & $2(0.5)$ \\
\hline
\end{tabular}




\begin{tabular}{|l|l|}
\hline Time of vaccination inconvenient & $2(0.5)$ \\
\hline Mother too busy & $29(7.4)$ \\
\hline Plan to do it later & $32(8.2)$ \\
\hline Forgot to take child for vaccination & $4(1.0)$ \\
\hline Husband/head of householder won't allow & $31(8.0)$ \\
\hline Unable to pay for vaccination services & $0(0.0)$ \\
\hline Unable to pay for transport & $1(0.3)$ \\
\hline family problem, like illness of mot & $3(0.8)$ \\
\hline Child ill, mother refuse & $11(2.8)$ \\
\hline Child ill, vaccinator refuse & $0(0.0)$ \\
\hline Vaccinator not available at facility & $1(0.3)$ \\
\hline Vaccinator absent & $0(0.0)$ \\
\hline Long waiting line & $1(0.3)$ \\
\hline Did not know needed other vaccine & $15(3.9)$ \\
\hline Feel vaccination not important & $33(8.5)$ \\
\hline Do not trust vaccines & $39(10)$ \\
\hline Fear of side effect/ adverse event & $21(5.4)$ \\
\hline Cultural/ religious reasons & $11(2.8)$ \\
\hline Unaware of place/time of vaccination & $6(1.5)$ \\
\hline
\end{tabular}

Table 4.5: Reasons given by care givers on why they don't have a vaccination cards for his/her child right now?

\begin{tabular}{|c|c|}
\hline Reasons given & $\begin{aligned} \text { Chi square } \mathrm{x}^{2}= & 168.28 \mathrm{p}<0.05^{\alpha}=0.001 \\
& \mathbf{N}(\%)\end{aligned}$ \\
\hline 1. Card not given to mother/caregiver & $17(5.2)$ \\
\hline 2. Card not available now/outside house & $12(3.7)$ \\
\hline 3. Card lost & $56(13.3)$ \\
\hline 4. Card not available at the clinic & $6(0.9)$ \\
\hline $\begin{array}{l}\text { 5. Mother/ caregiver asked to pay for } \\
\text { card }\end{array}$ & $3(0.9)$ \\
\hline 6. Child never went to clinic & $201(62.3)$ \\
\hline 7. Don't know & $23(7.1)$ \\
\hline 8. Other, specify & $5(1.6)$ \\
\hline Total & $323(100)$ \\
\hline
\end{tabular}

Table 4.6: what information would help mothers decide to vaccinate their children through routine immunization service?

\begin{tabular}{|c|c|}
\hline Information & $\mathbf{N}(\%)$ \\
\hline 1. Safety of the vaccine & $62(15.9)$ \\
\hline 2. Side effects of the vaccine & $44(11.3)$ \\
\hline 3. Why vaccinating of my child is important & $87(22.3)$ \\
\hline 4. What diseases vaccines protect against & $99(25.4)$ \\
\hline 5. If sick children can receive the vaccine & $30(7.9)$ \\
\hline 6. Time/ place for routine vaccination near my home & $12(3.1)$ \\
\hline 7. Schedule for vaccination of child & $14(3.6)$ \\
\hline 8. Whether my husband/ family approves & $16(4.1)$ \\
\hline 9. Whether my religious leader approves & $6(1.5)$ \\
\hline 10. Whether my community leader approves & $2(0.5)$ \\
\hline 11. Others, specify & \\
\hline
\end{tabular}


South American Journal of Public Health

Special Edition May 2016

\subsection{Discussion}

Estimated global DPT3 coverage among children aged $<12$ months in 2013 was $84 \%$, ranging from $75 \%$ in the WHO African Region to $96 \%$ in the Western Pacific and European regions (Jennifer et al, 2014). During same year, a total of 129 of 194 WHO member states achieved $\geq 90 \%$ national DPT3 coverage, and 56 achieved $\geq 80 \%$ DTP3 coverage in every district. DPT3 coverage was $80 \%-89 \%$ in 31 countries, $70 \%-79 \%$ in 16 countries, and $<70 \%$ in 18 countries (WHO, 2015).

In Nigeria by 2013 the national coverage for the DTP3/PENTA 3 is $84 \%$ which was much higher than 52\% in 2012 (NPHCDA, 2013). The country has witnessed a marked improvement in routine immunization uptake from DPT coverage of $50 \% 2+$ years ago to about $84 \%$. Also Nigeria achieved $66 \%$ reduction in unimmunized children from Jan-Dec 2013 compared to same period in 2012 ( NPHCDA, 2013).

In Jigawa State according to the NPHCDA and state Ministry of health report Jigawa State recorded the highest immunization coverage of over $80 \%$ in 2013 (NPHCDA, 2013) against the $24 \%$ and $14 \%$ of 2007 and 2008 respectively (PRRIN, 2014) this is due to increase in health care budget funding by the State Government, and five years' work of PRRIN-MNCH( Partnership for transforming routing immunization in Northern Nigeria) a DFID (Department for international Development) funded project also assist in transforming the immunization coverage of the state.

In Miga local Government which is one of the local government areas with over $75 \%$ rural settlement according to this survey recorded $8.5 \%$ routine immunization coverage with penta3. While fully immunized stood at 7\%. This result is by far below the 2013 Global, National and Jigawa State immunizations coverage that's means $91.5 \%$ of the children age 11-23 months have not received doses of DPT/Pentavalent vaccines in their life by June 2015. This suggested inequalities in health care in:

1) Local Government areas between Urban and rural areas where by $23.1 \%$ of urban settlement are fully immunized while only $4.9 \%$ of rural settlements are fully immunized.

2) The State where the state average in RI coverage is $84 \%$ in 2013. Miga has recorded $8.5 \%$ in 2015 (which is 10 fold lower)

3) Nigeria, the national average in RI coverage was $83 \%$ (NPHCDA, 2013) while $8 \%$ is recorded in other part of the same country (Miga).

According NPHCDA 2013 report north west zone of the country where Miga is also located has the highest number of un immunized children in the country about 954,394 in 2012 (NPHCDA 2013)

The main determinants responsible for the low immunization coverage in Miga LGA identified are: sex, parity, parents educational level other factors include lack of knowledge and awareness of vaccination, Mass media awareness, and insufficient information on vaccines safety. Parent stress that they needed more information on which diseases does the vaccines prevent, Also there are strong relationship between parental education/information on routine immunization and completeness of routine immunizations.

The survey in Miga is by far away from the administrative coverage which was indicating about $79 \%$ coverage (SMOH 2014) there is about 10 fold difference. According to WHO (2005) Immunization coverage surveys are conducted for any of the following reason

1) As supplemental information to compare with administrative coverage report.

2) Providing information for service assessment.

3) Assessing the change in coverage over time, geographic areas or population groups

4) Assessing coverage achieved in a supplemental immunization activity(SIA)

5) Providing information on immunization coverage demanded by funding and other agencies

Confounding factors: associated with low RI coverage are: not taking the child to the clinic: all factors that can prevent the child from visiting clinic such as distance to the health facility cost of transportation, non-permit from husband. Non execution of outreaches season 
plans by the health worker confounded in the higher number of unimmunized children in the LGA.

Maternal education shows highly positive relationship with completion of routine immunization as demonstrated by other researches by Babalola (2009) and Adeyinka et al., (2009) in separate work found out that highly educated mothers are more aware of the importance of vaccine and mostly completed their children immunization. Mass media exposure showed a strong positive relationship with immunization status as demonstrated by Nath et al(2007), also information from health worker assisted in vaccination recall, keeping RI card and found to reduce Pentavalent dropout rate.

Knowledge on immunization was also found to have a good relationship with completion of routine immunization. There is need to focus on strengthening of awareness strategies (Lillian et al, 2012; Saheed et al, 2010). 62.3\% of those without immunization cards responded as their child never went to clinic because of RI. In coverage surveys, parents of older children are less likely to have home-based vaccination records and are more likely to have poor recall of vaccinations (Jennifer et al, 2014)

\subsection{Strength of the study}

Knowledge of terrain and culture of the study area before the survey is a major strength of this study. Larger sample size population of 13 per cluster used in this survey which almost doubles the Gold standard of 7 per cluster recommended by the WHO is an added strength of the study. The larger the sample sizes the better.

\subsection{Limitation of the study}

The researcher did his best to minimize the recall bias by confirming and reconfirming the immunization status by enquiring about the various aspects of the vaccine, such as name, site and age of administration; but as it is with any other study, it could not be totally eliminated. All effort was done to minimize interviewer bias such as using random table number was the eligible child is more than one. The study could also not study the inadequacies related to the health care delivery aspects, such as conducting out reaches in villages more than 5 kilmetres from the nearest health facility, which may be responsible for the low immunization coverage.

Immunization card was used as the goal standard probe of the completeness of the routine immunization, however many mothers cannot trace their child immunization card there by lowering the immunization coverage. In coverage surveys, parents of older children are less likely to have home-based vaccination records and are more likely to have poor recall of vaccinations. (Jennifer et al, 2014).

Male interviewers were used in few Fulani (herdsmen) settlement and hard to reach clusters, because most of the Fulani /herdsmen had dogs and the ladies are afraid, also we had to use horses to access some of the Fulani/herdsmen muddy settlement after heavy rain fall. Distance to the nearest health facility is not measured in this study.

\section{Conclusion and recommendations}

The utilization of routine immunization services in Miga LGA Jigawa State, Nigeria is far below the national and international levels. All Stake holders have to unite to come out with special community mobilization and health education interventions to address the main determinants identified such as maternal education, mass media awareness campaigns, knowledge and information regarding immunization services. However we cannot conclude that the following have a direct significant relationship with full immunization coverage Sex, Parity and fathers education.

\section{Recommendations:}

Low immunization coverage has debilitating consequences on the lives of the children. To improve the immunization uptake, it is recommended that health education/promotion programs such sensitization work Shops, Radio jingles, Community enlightenment campaigns on immunization be conducted in local languages. Routine immunization outreaches had to be 
South American Journal of Public Health

Special Edition May 2016

conducted as schedule as well as continual social support such as National Health insurance scheme. free drugs for pregnant and under 5 children and Gift/Certificate be provided for completing routine immunization to reduce the high dropout rate and be part of the LGA's holistic public health/promotion program to save the underserved children.

\section{References}

[1.] Annual Program Activity and progress implementation report 2013 pg28-29 by NPHCDA.

[2.] Adeyinka, D.A., Oladimeji, O., Adeyinka, F.E., \&Aimakhu, C. (2009). Uptake Of Childhood Immunization Among Mothers Of Under-Five In Southwestern Nigeria. The Internet Journal of Epidemiology, 7.doi: DOI: 10.5580/f4 Antai, D. (2009). Faith and child survival: the role of religion in childhood immunization in Nigeria. Journal of Biosocial Science, 41(01), 57-76

[3.] Babalola, S. (2009). Determinants of the Uptake of the Full Dose of Diphtheria-Pertussis Tetanus Vaccines (DPT3) in Northern Nigeria: A Multilevel Analysis. Maternal Child Health Journal 13, 550558. Centre for Disease control and prevention (CDC) (2010).

[4.] Burton A, Monasch R, Lautenbach B, et al. WHO and UNICEF estimates of national infant immunization coverage: methods and processes. Bull World Health Organ 2009;87:535-41.

[5.] CDC. Global routine vaccination coverage, 2010. MMWR Morb Mortal Wkly Rep 2011;60:15202.

[6.] Federal Ministry of Health, National Primary Health Care Development Agency. Comprehensive EPI Multi-Year Plan 2009 - 2014

[7.] GHO Global Health Observatory Data 2015

http://www.who.int/gho/publications/world_health_statistics/2015/en/

[8.] Improving Routing Immunization in Northern Nigeria Apr,2013(PRRIN -MNCH) report.

[9.] Jennifer B. Harris, PhD1, 2, Marta Gacic-Dobo, MSc3, Rudolf Eggers, MD3, David W. Brown,

DSc 4, Samir V. Sodha, "MDI 1 Global Immunization Division, Center for Global Health, CDC; 2

Epidemic Intelligence Service, CDC; 3 Department of Immunization, Vaccines and Biological, World Health Organization; 4 Division of Data, Research and Policy, United Nations Children's Fund (Corresponding author: Jennifer Harris, jbharris@cdc.gov, 404-639-4498) NOV 2014

[10.] LilianChepkemoi Maina1,\&, Simon Karanja1, Janeth Kombich2 1Institute of Tropical Medicine and Infectious Diseases, Jomo Kenyatta University of agriculture and Technology. P.O.BOX 6200000200 Nairobi, Kenya, 2Kabianga University College, P.O. Box 2030, 20200, Kericho, Kenya 2012. [11.] Miga LGA WHO facilitators November 2014 IPDs report.

[12.] Nath B, Singh J V, Awasthi S, Bhushan V, Kumar V, Singh S K. A study on determinants of immunization coverage among 12-23 months old children in urban slums of Lucknow district, India. Indian J Med Sci2007;61:598-606 http://www.indianjmedsci.org/text.asp?2007/61/11/598/37046 [13.] National Primary Health Care Development Agency. National Immunization Coverage Survey; 2003

[14.] PRRIN Jigawa state exit Data presentations 2014.

[15.] Research advisors sample size time table 2006 Google web site (http://research.advisors.com) [16.] SaheedGidado, ,Kabir Sabit and 10 Others Determinants of routine immunization coverage in Bungudu, Zamfara State, Northern Nigeria, May 2010

[17.] Salako AA, Oluwole AF. An Appraisal of Immunization in Nigeria: Towards Improving Coverage. Nigerian Hospital Practice. 2009;3(3-4)

[18.] SMOH (State Ministry of Health ) Jigawa State Task force on immunization presentation Jan 2015

[19.] Tagbo, B.N., Eke, C.B., Omotowo, B.I., Onwuasigwe, C.N., Onyeka, E.B. and Mildred, U.O. (2014) Vaccination Coverage and Its Determinants in Children Aged 11 - 23 Months in an Urban District of Nigeria. World Journal of Vaccines, 4, 175-183. http://dx.doi.org/10.4236/wjv.2014.44020

[20.] Vanguard Nigeria news paper $26^{\text {th }}$ June, 2012 www.vanguardngr.com/.../new.pentavalent2012

[21.] www.who.int/mediacentre/factsheets/fs378 Cached Fact sheet from WHO

on immunization coverage: provides key facts and information about recommended vaccines, key challenges and WHO response.(2015) 
[22.] World Health Organization. Expanded Programmed on Immunization: Routine Immunization Schedule in Nigeria. 2009 www.int.org

[23.] WHO immunization coverage Cluster Survey Reference Manual, Department of Immunization Vaccines And Biological http//www.who.int/vaccines.documents. (WHO_IVB_04.23.pdf) 2005

[24.] WHO Jigawa State Task force on immunization presentation Jan 2015

[25.] Wikipedia the free encyclopedia Jigawa State $2015 \mathrm{https} / /$ en.m,Wikipedia.Jigawa_state

[26.] WHO Regional office for Africa web site /news Nigeria launches penta vaccines www.afro.who.int/.../nigeria/.../4735 June 2012 